\title{
Erratum
}

\section{Effect of thyroid status on $\beta$-adrenoceptors and calcium channels in rat cardiac and vascular tissue}

\author{
M. H. Hawthorn, P. Gengo, X.-Y. Wei, A. Rutledge, J. F. Morau, S. Gallant, and D. J. Triggle \\ Naunyn-Schmiedeberg's Arch Pharmacol (1988) 337:539-544
}

Due to an unfortunate error, Figs. 1 and 2 were inadvertently exchanged for each other. The correct figures are reprinted below:
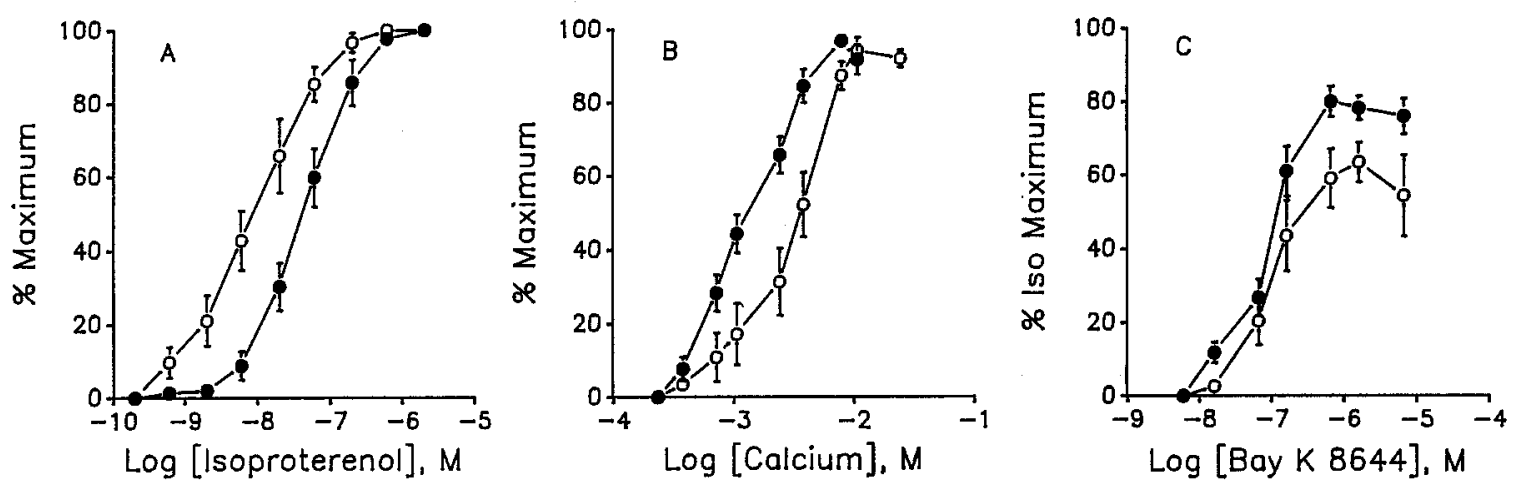

Fig. 1. Mean concentration-response curves for the positive inotropic responses of rat papillary muscles to (A) isoproterenol, (B) calcium, (C) Bay K 8644. Tissues were taken from euthyroid (untreated) (O), hypothyroid $(\boldsymbol{O})$ and hyperthyroid $(\mathbf{A})$ animals. Responses to isoproterenol and calcium are plotted as an increase in tension expressed as a percentage of the maximal increase. Responses to Bay $\mathrm{K} 8644$ were plotted as a percent of the maximal response to isoproterenol (Iso). Vertical bars represent SE $(n=7-9)$
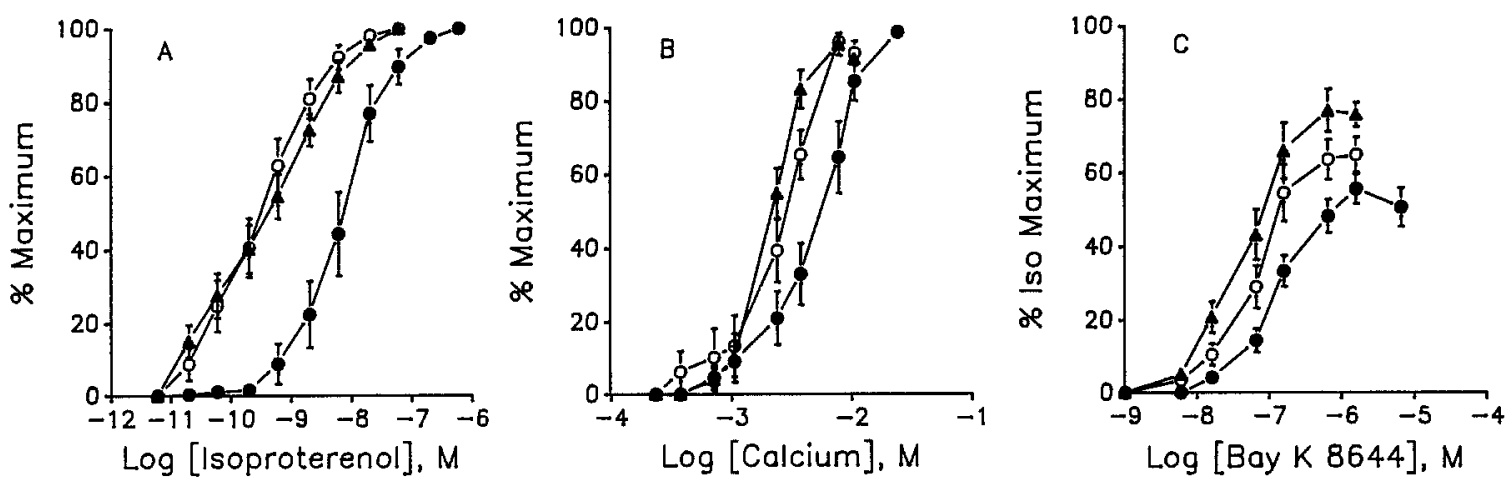

Fig. 2. Mean concentration-response curves for the positive inotropic responses of rat left atria to (A) isoproterenol, (B) calcium, (C) Bay K 8644. Tissues were taken from euthyroid (untreated) $(\bigcirc)$, hypothyroid $(\mathbf{O})$ and hyperthyroid $(\mathbf{A})$ animals. Responses to isoproterenol and calcium are plotted as an increase in tension expressed as a percentage of the maximal increase. Responses to Bay $\mathrm{K} 8644$ were plotted as a percent of the maximal response to isoproterenol (Iso). Vertical bars represent SE $(n=7-9)$ 